\title{
Exploring social customer relationship management in Australian small and medium enterprises
}

\author{
Kritcha Yawised \\ School of Engineering and ICT, \\ University of Tasmania, \\ Private Bag 87, \\ Hobart, Tasmania, 7001 Australia \\ Email: Kritcha.Yawised@utas.edu.au \\ Nuttaneeya (Ann) Torugsa* \\ Australian Innovation Research Centre, \\ University of Tasmania, \\ Private Bag 108, \\ Hobart, Tasmania, 7001 Australia \\ Email: Nuttaneeya.Torugsa@utas.edu.au \\ ${ }^{*}$ Corresponding author
}

\section{Wayne O'Donohue}

Department of Employment Relations and Human Resources,

Griffith University,

Gold Coast Campus,

Queensland, 4222 Australia

Email:w.odonohue@griffith.edu.au

\begin{abstract}
Social customer relationship management (SCRM) is a new business concept and strategy that utilises and integrates social networking with 'traditional' CRM processes and strategies in order to bring about superior engagement with customers. There is a paucity of scholarly empirical research into SCRM in small and medium enterprises (SMEs). This paper describes the first large-scale survey-based study in Australia that explores the role and nature of SCRM in SMEs. Using a sample of 967 Australian SMEs (comprising 540 SCRM adopters and 427 SCRM non-adopters) and employing both descriptive and simple inferential statistics, we investigate the current level of SCRM adoption, types of social networking sites used with SCRM, business objectives for SCRM engagement, methods of sourcing or implementing a SCRM system, SCRM implementation-related activities, as well as the benefits and barriers related to SCRM implementation. The study results reveal that SCRM adoption by Australian SMEs has been relatively ad hoc, superficial (even primitive) and usually not supported by a formal integrated strategy and policy framework. Although SMEs that have adopted SCRM did so with the expectation of benefits, particularly in terms of building brand and establishing customer loyalty/intention, the study shows that SCRM benefits are often not immediately apparent in the short term; the results also indicate that lack of time and knowledge of how to implement SCRM effectively are critical barriers to successful SCRM adoption by SMEs. Our findings suggest further research is needed in this area.
\end{abstract}


Keywords: small and medium enterprises; social customer relationship management; social networking; SCRM; SME.

Reference to this paper should be made as follows: Yawised, K., Torugsa, N. and O'Donohue, W. (2017) 'Exploring social customer relationship management in Australian small and medium enterprises', Int. J. Globalisation and Small Business, Vol. 9, No. 4, pp.222-251.

Biographical notes: Dr Kritcha Yawised holds a $\mathrm{PhD}$ in Information Technology from the School of Engineering and ICT, University of Tasmania in Australia. His research interests include social customer relationship management, social networking technologies, Web 2.0 tools, and e-marketing. Dr Yawised previously worked as an IT technical support specialist at Hydro Tasmania, Australia's leading renewable energy company.

Dr Ann Torugsa is a research fellow at the Australian Innovation Research Centre, University of Tasmania in Australia. Her research interests cover innovation management and policy, corporate social responsibility, innovative research design, and strategic management in general, and cut across sectoral and disciplinary boundaries. $\mathrm{Dr}$ Torugsa's work involves applying econometrics to the analysis of large-scale surveys obtained from national and international sources, and testing theoretical models which organisations can apply in choosing strategies that contribute to performance improvement. Her work appears in journals such as Research Policy, Journal of Business Ethics, Journal of Business Research, Public Management Review, Australian Journal of Public Administration, International Journal of Innovation Management, International Journal of Human Resource Management, and Human Resource Management Journal.

Dr Wayne O'Donohue is a senior lecturer in the Griffith Business School, Griffith University in Australia. His primary research interests are in the areas of organisational behaviour, human resource management, psychological contracts, professional work values, and psychological capital. Dr O'Donohue's work appears in journals such as the International Journal of Human Resource Management, Human Resource Management Journal, Journal of Business Ethics, Journal of Business Research, Journal of Knowledge Management, International Journal of Innovation Management, International Journal of Organisational Analysis, and Organisation Development Journal.

\section{Introduction}

The emergence of social networking has changed the way people and businesses interact via the internet (Greenberg, 2009; Sensis, 2016). Social networking involves the use of social media tools or social networking sites (e.g. Blogs, Wikis, Facebook, LinkedIn, Twitter, etc.) that foster interactive communication and collaborative information sharing via Web 2.0 technologies (Mosadegh and Behboudi, 2011). Social networking contains a large body of information on product and service providers and extends interactive communication that encompasses a wide range of online word-of-mouth sources to address a broader audience. This differs considerably from the traditional communication channels which limit interactions essentially to two persons (a sender and a receiver), leaving large audiences to be addressed through mono-directional channels such as email, 
static websites, television and newspapers (Barnad et al., 2017; Mangold and Faulds, 2009; Straker and Wrigley, 2016).

The rapidly growing popularity of social networking sites (SNS) has been evident worldwide. For example, in 2015, social networking penetration in Europe and in the United States reached 65 and $71 \%$ of all internet users, respectively (Pew Research Centre, 2016). A similar trend has occurred in Australia, where 69\% of Australian internet users had a social networking profile in 2015 (Sensis, 2016). This trend towards online communication is fundamentally changing the world of business; particularly, in the case of small and medium enterprises (SMEs), which make up over $90 \%$ of business worldwide (see the United Nations Industrial Development Organisation, 2005), where the use of online communication can open up a cost-effective way for firms with limited resources to market their business and increase their visibility and reputation (Cooper and Burke, 2011).

In essence, companies now have two options for communicating and engaging with their customers and managing their market presence

i the traditional customer relationship management (TCRM) approach, built on faceto-face interactions and one-to-one communication, with associated information systems that allow companies to control their market presence through the recording and management of detailed data and knowledge about current and prospective customers, markets and transactions

ii the new social customer relationship management (SCRM) approach using social networking and associated technologies to facilitate engagement and communication with customers, via online SNS-linked communities formed independently by people wishing to connect interactively with each other and share information, mutual interests and experiences about products and companies. This second option, which heralds a shift in the power balance between a company and its customers, carries with it an inherent threat for many companies; that is, the potential loss of control by a company over its market presence resulting from non- or ineffective adoption of social networking as a customer relationship management tool (Berthon et al., 2008). While both the traditional and online worlds are connected in the sense that the 'share of voices' in social networking is highly related to the 'share of market' (Rappaport, 2010), the challenge of how to integrate the traditional and new methods for managing customer relationships remains a significant one for companies, especially in the case of SMEs where prior research has found that many do not yet have the knowledge, skills and resources to capitalise on the potential business opportunities that social networking and SNS are able to provide (Boyles, 2011; Carson, 2013).

SCRM is a new business approach that integrates social networking with TCRM systems, technologies and processes to bring about a superior engagement with customers (Greenberg, 2010). While the role of SCRM in business has received significantly growing attention by practitioners (see consultant reports such as Keuky and Clarke, 2011; Reinhold and Alt, 2012; Sarner et al., 2010; Wang and Owyang, 2010), so far there has been little empirically based and rigorous academic research in this topic. Preliminary academic research efforts are beginning to be published in the United States and Europe (Acker et al., 2011; Faase et al., 2011; Greenberg, 2010), but no large-scale empirical 
research in SCRM adopted by SMEs has been completed in Australia (Yawised et al., 2013). This paper contributes to overcoming this gap in knowledge.

In this paper, we aim to investigate the role and nature of SCRM in contemporary Australian SMEs by addressing the following research questions:

- What is the current level of SCRM adoption in SMEs?

- What are the common social networking sites used by SMEs in relation to SCRM?

- What are the objectives for SMEs engaging in SCRM?

- What methods of sourcing or implementing a SCRM system are employed by SMEs?

- What are the common SCRM implementation-related activities employed by SMEs?

- What are the beneficial outcomes of SCRM implementation as perceived by SMEs?

- What are the barriers to implementing SCRM as perceived by SMEs?

Note that due to the limited number of large-scale surveys of this kind in the literature, this paper is to a large extent exploratory. We expect the study findings - which are reported in descriptive statistics (frequencies and percentages) and simple inferential statistics (chi-square and analysis of variance) - to result in an increased understanding of SCRM implementation in Australian SMEs and to motivate further research in this area.

\section{Literature review}

\subsection{Social customer relationship management}

SCRM combines two key concepts: social networking (also called social media) and TCRM. Social networking refers to internet-based technologies used for social interaction such as Blogs, Wikis and social sharing platforms. TCRM as a business strategy involves the use of traditional media and one-to-one marketing to organise, automate and synchronise business processes to develop, manage and maintain long-term profitable customer relationships. Emphasising an internal operational approach for managing customer relationships, TCRM uses only specific information provided by the customer, or customer-specific information that is already known to a company (Askool and Nakata, 2011; Newby et al., 2014).

While SCRM has been defined in a variety of ways in the literature with a clear-cut consensus yet to emerge, a popular characterisation has been that of Greenberg (2009) who defines SCRM as "a philosophy and a business strategy, supported by a technology platform, business rules, processes and social characteristics, designed to engage the customer in a collaborative conversation in order to provide mutually beneficial value in a trusted and transparent business environment. It's the company's response to the customer's ownership of the conversation" (p.34). A succinct definition of SCRM has also been provided by Kotadia (2010, p.1), supported by Woodcock et al. (2011, p.52), as "the business strategy of engaging customers through social media with goal of building trust and brand loyalty." 
On this basis, SCRM can be viewed as having two primary objectives: building 'trust' and establishing 'customer loyalty'. While these objectives are similar to those of TCRM, there exists a key difference between the two approaches. TCRM is aimed at 'customer management', and involves careful customer segmentation (at a macro, micro or one-to-one level) depending on existing and potential profitability (Knox et al., 2003; Payne and Frow, 2006). The data generated from TCRM are typically highly structured, making them easy to manage, interpret and use for customer management purposes (Buttle and Maklan, 2015). On the other hand, SCRM which is aimed at 'customer engagement' (Greenberg, 2009) has a holistic focus emphasising the complete experience that engages customers (Marolt et al., 2015; Stone, 2009; Woodcock et al., 2011). Concerned with interactions between individuals within social networks, SCRM generates huge volumes of data that are unstructured and difficult to manage (Buttle and Maklan, 2015).

Notwithstanding these key differences, SCRM is an extension of, rather than a replacement for, TCRM (Woodcock et al., 2011). Both SCRM and TCRM include strategies and technologies that require detailed knowledge about customers and market needs. However, by integrating social networking with existing TCRM processes, SCRM enhances TCRM and adds greater value by improving the quality of the customer relationship through more meaningful interactions (Acker et al., 2011; Greenberg, 2009; Maecker et al., 2016). SCRM is not just a technology upgrade; rather, it is designed to produce a fundamental and positive change in the quality and effectiveness of a firm's interactions with its customers, thereby making such interactions more profitable for the organisation (Ang, 2011). Adoption of SCRM enables a firm to connect and integrate social networking and the customer-oriented service systems of a firm. The difficulty in achieving this integration should not be understated, however, given that the quality of customer-firm interactions depends strongly upon both the degree to which existing knowledge about customers and markets can be utilised and whether the relevant information can be identified through social networking and SNS (Rappaport, 2010; Sarner et al., 2011).

\subsection{SMEs and IT}

SMEs are a significant part of every economy, and in most developed nations are accepted as being the predominant employers and wealth generators. Despite their importance, there is no universally accepted definition of SMEs. The European Commission (2005) defines SMEs based on employee numbers, annual turnover and balance sheet total (i.e. the value of a firm's main assets), while the Australian Bureau of Statistics (2011) defines SMEs based only on employee numbers. For the purpose of this study, which was done in the Australian business context, we use staff numbers, with an upper limit of less than 200 employees, as the demarcation measure: hence, a micro-sized enterprise is defined as employing less than five employees; a small enterprise employs 5-19 employees; and a medium enterprise has 20-199 employees. Our definitional approach is consistent with the Australian Bureau of Statistics (2001) and with previous SME research (Burgess et al., 2009; Sensis, 2014). It is also appropriate in the Australian context where $99.8 \%$ of all firms are classified accordingly as SMEs (see the Department of Industry, Innovation, Science, Research and Tertiary Education [DIISRTE], 2012). 
Research shows that the smaller the business is, the lower the adoption rate of information technologies (IT) (Bordonabe-Juste et al., 2012; Burgess et al., 2009; Kim et al., 2013). In 2010-2011, 32.2\% of Australian micro-sized firms had an internet presence, compared to $53.8 \%$ of small firms, $73.9 \%$ of medium firms and $97.3 \%$ of large firms (DIISRTE, 2012). A recent study by Sensis (2014) showed that the levels of IT adoption in Australia, with respect to the proportion of internet connections, business websites and ownership of digital devices, were lower for micro-sized and small firms than for medium firms. In terms of IT-based social networking, the Sensis's (2014) study found that $35 \%$ of Australian SMEs connected to the internet had some type of social networking presence, with the most popular types of SNS being Facebook (used by $93 \%$ of these SMEs with internet connections), Twitter (28\%) and LinkedIn (17\%). Overall, about half of SMEs using social networking reported that its impact on their business was positive (Sensis, 2014). On the other hand, Aaltonen et al. (2013) in a study of European SMEs reported that although $61 \%$ of SMEs used SNS for business purposes, most of the usage was not organised, with only $27 \%$ having a specific policy in place for SNS.

Various reasons have been used to explain the differential in the adoption rate for technology generally, and IT-based social networking in particular, between large firms and SMEs. In relation to SMEs, these include a lack of knowledge and expertise on how to use social networking technologies and SNS effectively; insufficient time to devote to developing skills for the effective use of social networking and SNS; and a lack of ability to access the necessary financial and other resources for evaluating the suitability and appropriateness of the available SNS options (Boyles, 2011; Harrigan and Miles, 2014). Research also suggests that SMEs can perceive themselves to be at a competitive disadvantage in the use of IT because of a lack of resources and a consequent dependence on IT strategies that reflect the often less than sophisticated IT skill levels and low risktaking tendencies of owner-managers (Burgess et al., 2015; Fux et al., 2007). Moreover, Carson (2013) also found that SMEs often underestimate the complexity of available technology, and especially the significant opportunities for becoming more strategic, efficient and effective that the new social networking technologies offer.

\subsection{SMEs and SCRM}

The question of whether to adopt SCRM as part of a coherent suite of business strategies is rarely formally addressed in SMEs; if an initiative is taken, it tends most often to be driven by the experience and interests of the individual owner-manager. Dyerson et al. (2009) indicate that the use of IT in TCRM by SMEs often emphasises operational objectives, ignoring the opportunities for more strategic uses, such as facilitating interaction with and engagement of customers, collecting customer- and market-specific information through dynamic websites, and enhancing the firm's image and reputation. An emphasis on short-term operational and tactical objectives in the use of IT that ignores the strategic potential of SCRM often occurs in a context where the implementation of customer-oriented technologies (e.g. SNS or Web 2.0 applications) is perceived as a cost issue rather than as an investment. This perception means that SMEs are likely to adopt SCRM only when they fully understand how it facilitates interaction with and the engagement of customers, and thus have confidence that it can add business value and provide a realisable return on investment (Harrigan and Miles, 2014; Wielicki and Arendt, 2010). For example, a study of Canadian SMEs by Cappuccio et al. (2012) 
indicates that the potential benefits of SCRM to SMEs include enabling them to build a wider customer base locally and internationally; predict future market trends and customer behaviours; create knowledge resources that derive from the network of conversations and collaborations between the firm and its customers; and increase the return on investment from customer relationship management activities. However, a lack of confidence in its benefits, as well as insufficient knowledge and skills relating to markets and customer-oriented technologies, often inhibit adoption of SCRM by SMEs.

However, it should be noted that SCRM may not equally benefit all SMEs in all industry/market segments. Setting up of an SNS-based community for SCRM purposes can be demanding in terms of cost and time (Cappuccio et al., 2012; Olupot et al., 2014; Stone, 2009). Furthermore, since the forms of data generated from SCRM are unstructured and plentiful (Buttle and Maklan, 2015), integrating them into structured databases can pose significant challenges for SMEs. For many SMEs, the investment of scarce resources in developing the integrated customer database which serves as a foundation component in SCRM might well lead to system implementation costs exceeding the likely immediate benefits, with the full benefits only able to be acquired over an unacceptably long timescale. Negative reactions by staff to change, the potential loss of confidential commercial information and the security risks that attend an open communication environment (problematic in the financial and insurance service sector) can also act as significant impediments to, or as constraints on implementation of SCRM (Cappuccio et al., 2012; Harrigan and Miles, 2014; Olupot et al., 2014). Indeed, in the light of these sorts of resourcing and implementation difficulties, it is not unreasonable that an SME might opt to retain the traditional way of cultivating positive customer experiences.

\section{Methods}

In this study, an online survey was used to sample 9,000 Australian SMEs with less than 200 employees across all sectors, randomly selected from the population of Australian private firms listed in the Dun and Bradstreet (Australia) database. The survey was conducted during July-November 2013. Since SCRM implementation entails processes related to IT and marketing functions (Huang and Wang, 2013; Olszak and Bartus, 2013; Payne and Frow, 2005), the questionnaire was sent to the Chief Executive Officers or senior managers whose main responsibility at their firm was either IT management, marketing management or both types of management combined. As no data on SCRM activities for the targeted sample population in Australia is publicly available, a survey questionnaire was developed based on the extant literature (Acker et al., 2011; Baird and Parasnis, 2011; Cappuccio et al., 2012; Dutot, 2013; Greenberg, 2009; Leary, 2008; Stone, 2009). The questionnaire was also pretested in discussion with several SME owner-managers as well as with senior academic researchers in the fields of IT and marketing to ensure clarity and content validity. Of 9,000 Australian SMEs surveyed, 1,064 responses were received. After deleting 97 responses with missing data, a total of 967 firms remained in the sample, representing a $10.7 \%$ response rate. 


\section{Results}

In the questionnaire, TCRM was defined as "a business strategy that drives functional plans, processes and actions towards establishing relationships with customers," and SCRM was defined as "the use of social networking or social media (e.g. Facebook, LinkedIn and Twitter) to enhance TCRM." Table 1 presents the data collected from survey respondents showing SCRM adoption by SME organisational characteristic. Of the 967 responding SMEs, 540 (55.8\%) reported SCRM adoption. Medium and small firms were more likely than micro-sized firms to engage in SCRM although the chisquare result was not significant. The industry sector to which firms belong mattered for SCRM adoption $\left(X^{2}=27.16, p<0.05\right)$. The three sectors with the highest share of firms adopting SCRM were arts and recreation services $(72.7 \%)$, accommodation and food services $(66.2 \%)$ and retail trade $(65.5 \%)$, whereas the manufacturing sector had the lowest share of SCRM adopters (43\%). In terms of market type, most SCRM tended to focus on business-to-customer (B2C) rather than business-to-business (B2B), where $58.4 \%$ of firms that served individual customers as an important market had engaged in SCRM, compared to $46.4 \%$ of firms that served other market types including other companies or other divisions of their firms $\left(X^{2}=9.61, p<0.001\right)$. Difference in the respondent's main job responsibility (IT, marketing or both types of management combined) had no significant impact on the decision to adopt SCRM.

Table 1 SCRM adoption by organisational characteristics

\begin{tabular}{|c|c|c|c|}
\hline Characteristics & $N$ & $\begin{array}{c}\text { Percentage of } \\
\text { companies adopting } \\
\text { SCRM (\% in row) }\end{array}$ & $\begin{array}{l}\text { Chi-Square } \\
\left(X^{2}\right)\end{array}$ \\
\hline \multicolumn{4}{|l|}{ Size of firm } \\
\hline \multicolumn{4}{|c|}{ Survey question: 'How many full-time equivalent employees are working in your company?' } \\
\hline Micro (under 5 employees) & 334 & 51.5 & 3.97 \\
\hline Small (5-49 employees) & 233 & 58.8 & \\
\hline Medium (20-199 employees) & 400 & 57.8 & \\
\hline \multicolumn{4}{|l|}{ Industry sector } \\
\hline \multicolumn{4}{|c|}{$\begin{array}{l}\text { Survey question: 'Please indicate the industry sector to which your company belongs, based on } \\
\text { the core business' }\end{array}$} \\
\hline Agriculture, forestry and fishing & 22 & 61.1 & $27.16^{*}$ \\
\hline Mining & 3 & 50.0 & \\
\hline Manufacturing & 40 & 43.0 & \\
\hline Electricity/gas & 5 & 55.6 & \\
\hline Construction & 31 & 48.4 & \\
\hline Wholesale trade & 25 & 44.6 & \\
\hline Retail trade & 93 & 65.5 & \\
\hline Accommodation and food services & 51 & 66.2 & \\
\hline Transport, postal and warehousing & 14 & 60.9 & \\
\hline Information media and telecommunications & 57 & 53.8 & \\
\hline
\end{tabular}


Table 1 SCRM adoption by organisational characteristics (continued)

\begin{tabular}{|c|c|c|c|}
\hline Characteristics & $N$ & $\begin{array}{l}\text { Percentage of } \\
\text { companies adopting } \\
\text { SCRM (\% in row) }\end{array}$ & $\begin{array}{l}\text { Chi-Square } \\
\left(X^{2}\right)\end{array}$ \\
\hline Financial and insurance services & 19 & 50.0 & \\
\hline Rental, hiring and real estate services & 9 & 45.0 & \\
\hline Professional, scientific and technical services & 70 & 54.7 & \\
\hline Administrative and support services & 12 & 50.0 & \\
\hline Public administration and safety & 6 & 54.5 & \\
\hline Education and training & 22 & 57.9 & \\
\hline Health care and social assistance & 29 & 55.8 & \\
\hline Arts and recreation services & 32 & 72.7 & \\
\hline \multicolumn{4}{|l|}{ Market type } \\
\hline \multicolumn{4}{|c|}{$\begin{array}{l}\text { Survey question: 'Which of the following are important markets for your company's products or } \\
\text { services?' }\end{array}$} \\
\hline Individual customers (B2C) & 443 & 58.4 & $9.61^{* * *}$ \\
\hline $\begin{array}{l}\text { Non-individual customers (incl. other companies or } \\
\text { other divisions of your company: B2B) }\end{array}$ & 97 & 46.4 & \\
\hline \multirow{2}{*}{\multicolumn{4}{|c|}{$\begin{array}{l}\text { Respondent's job responsibility } \\
\text { Survey question: 'What is your main responsibility at your company?' }\end{array}$}} \\
\hline & & & \\
\hline IT management only & 104 & 55.9 & 0.98 \\
\hline Marketing management only & 129 & 58.6 & \\
\hline Both IT and marketing management & 307 & 54.7 & \\
\hline All responding SMEs & 967 & 55.8 & \\
\hline
\end{tabular}

\subsection{SME implementation of SCRM}

As the aim of this study is to explore factors, methods and outcomes associated with SCRM implementation, the analysis in this section is restricted to the 540 SMEs (hereinafter referred to as 'SCRM adopters') that reported adoption of SCRM. Where relevant, the results are presented by firm size, industry sector, duration of a firm's experience in managing SCRM, and type of market served. Note that the smaller number of firms requires the use of a broader sector classification approach to protect confidentiality; to this end, Australian and New Zealand Standard Industrial Classification (ANZSIC) divisions have been aggregated into three broad industry sector categories

i industrial (including agriculture, forestry and fishing; mining; electricity/gas; and construction)

ii manufacturing 
iii services.

\subsection{SNS used with SCRM}

The list of SNS used in association with SCRM reported by SCRM adopters is shown in Table 2. Facebook dominates the social media space (cited by $87.2 \%$ of all SCRM adopters), followed by Google+ and LinkedIn being reported by a small majority of SCRM adopters (52.8 and 51.5\%, respectively).

Table 2 Social networking sites (SNS) used in association with SCRM

\begin{tabular}{|c|c|c|}
\hline$S N S$ & $N$ & $\begin{array}{c}\text { Percentage }(\%) \text { of SCRM adopters } \\
(N=540)\end{array}$ \\
\hline Facebook & 471 & 87.2 \\
\hline Google + & 285 & 52.8 \\
\hline LinkedIn & 278 & 51.5 \\
\hline Twitter & 263 & 48.7 \\
\hline YouTube & 224 & 41.5 \\
\hline Instagram & 62 & 11.5 \\
\hline MySpace & 34 & 6.3 \\
\hline SlideShare & 30 & 5.6 \\
\hline Flickr & 30 & 5.6 \\
\hline $\begin{array}{l}\text { Others e.g. SocialCam, Pinterest and } \\
\text { Vimeo }\end{array}$ & 38 & 7.1 \\
\hline
\end{tabular}

Note: Survey question: 'What specific social networking sites have your company used in association with SCRM? (select all that apply)'

The number of SNS used by SCRM adopters ranged from 1 to 9, with $61.9 \%$ using $1-3,34.8 \%$ using $4-6$ and $3.3 \%$ using $7-9$. Table 3 reports the means and standard deviations (S.D.) for the number of SNS by organisational characteristic.

The results of analysis of variance (ANOVA), shown in Table 3, revealed a significant difference in the mean scores of SNS numbers between the three categories of a duration of a firm's experience in managing $\operatorname{SCRM}(F=8.34, p<0.001)$, where firms with 3 years or more experience had a higher mean score $($ mean $=3.58)$ than those with less than 3 years of experience in managing SCRM. No significant differences in the mean scores of SNS number were detected for firm size, sector and market type. Table 3 also gives a detailed picture by organisational characteristic of the percentage of SCRM adopters for each type of SNS. Chi-square tests revealed a significant size effect on three types of SNS, including Facebook $\left(X^{2}=7.90, p<0.05\right)$, Google $+\left(X^{2}=22.98, p<0.001\right)$ and LinkedIn $\left(X^{2}=39.21, p<0.001\right)$. Specifically, medium firms used Facebook and Google+ more than (but used LinkedIn less than) small and micro-sized firms. No sectoral effects were observed. In terms of years of experience with SCRM, the longer the duration of a firm's experience with SCRM, the more likely LinkedIn $\left(X^{2}=\right.$ $6.71, p<0.05)$, Twitter $\left(X^{2}=10.98, p<0.01\right)$, Instagram $\left(X^{2}=11.39, p<0.01\right)$ and Flickr $\left(X^{2}=11.41, p<0.05\right)$ were employed to support SCRM implementation. The reverse applied to SlideShare, however, where SCRM adopters with experience of less 
than 1 year were most likely to use this SNS type $\left(X^{2}=7.54, p<0.05\right)$. For the type of market served, B2B market-oriented SCRM adopters were more likely to use LinkedIn $\left(X^{2}=16.41, p<0.001\right)$ and SlideShare $\left(X^{2}=7.54, p<0.05\right)$, but less likely to use Facebook $\left(X^{2}=17.92, p<0.001\right)$, compared to their B2C market-oriented counterparts.

Table 3 The number and type of social networking sites (SNS) used in association with SCRM by organisational characteristics

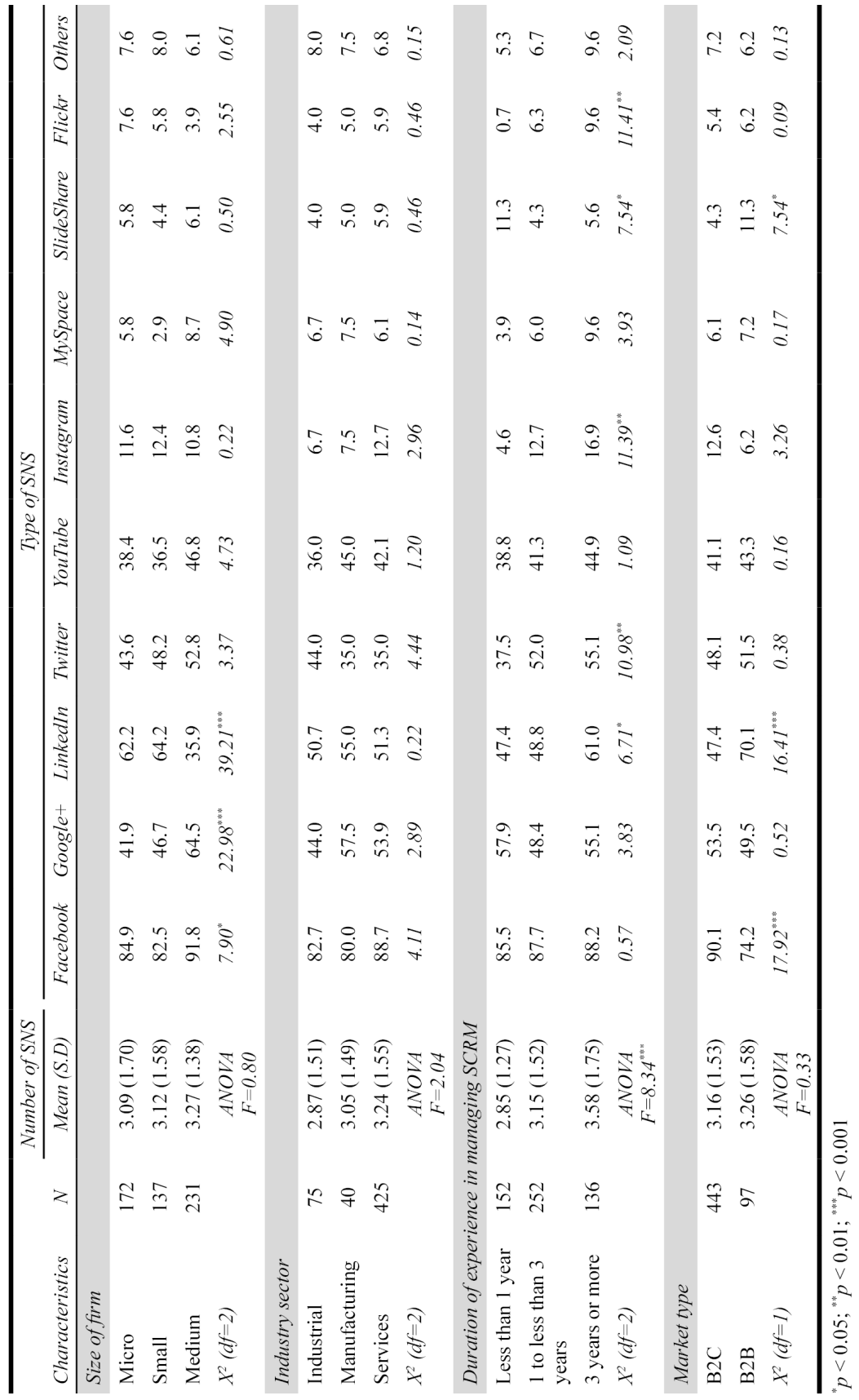




\subsubsection{Objectives for SCRM engagement}

Respondents were asked to rate eight possible objectives in relation to their firm's decision to adopt SCRM. Figure 1 shows the ratings as reported for these objectives by three categories of degree of importance: 'very high or high', 'medium' and 'low or not important'. Seven of the eight objectives were rated by more than half of SCRM adopters in the category of very high or high importance, with the three objectives most often rated at this level being: strengthening the company's brand (90.7\%); building and enhancing customer loyalty (79.6\%); and establishing and building trust-based relationships with customers $(79.3 \%)$. Reducing customer service costs was the objective rated least often by SCRM adopters (41.1\%) in the category of very high or high importance; similarly, it was also the objective rated most often by SCRM adopters (39.4\%) in the category of low or no importance (almost double the rating of the next objective in this category).

Figure 1 Objectives of SCRM engagement by degree of importance ( $\%$ SCRM adopters: N=540)

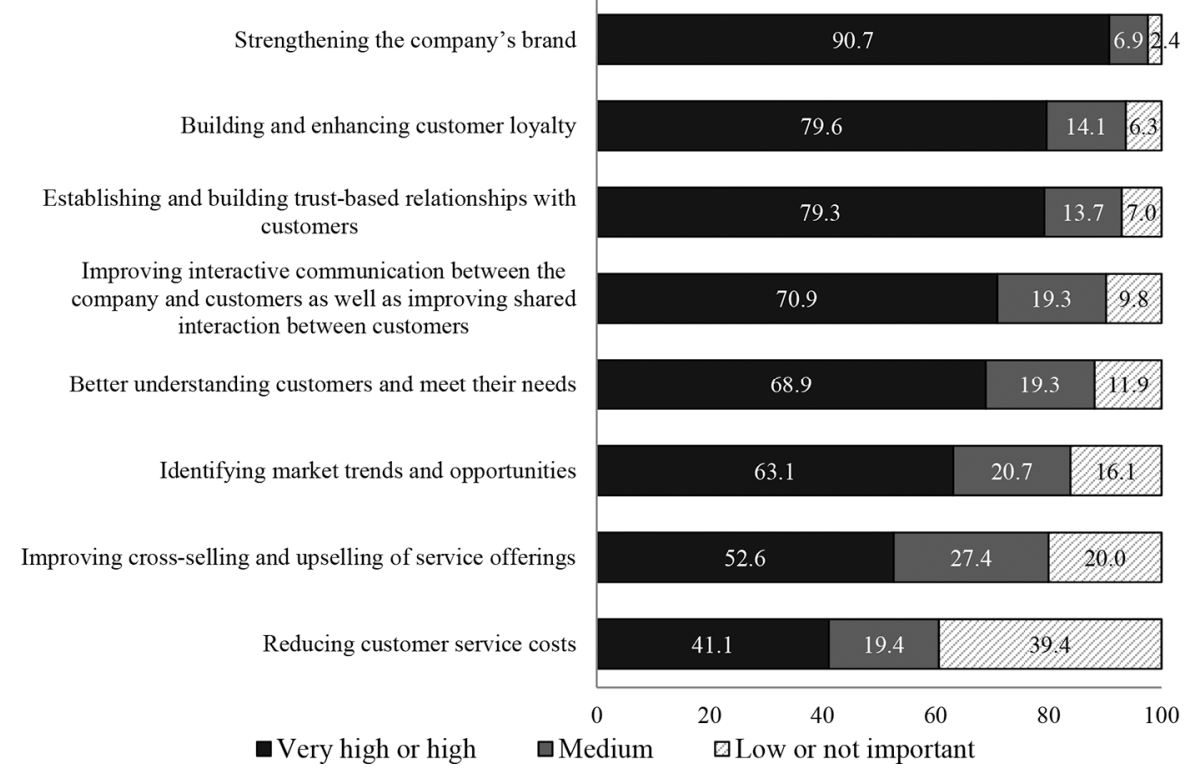

Survey question: 'How important were each of the following objectives for your company's decision to adopt SCRM?'

Table 4 provides the detailed picture by organisational characteristic of the percentage of SCRM adopters that rated each objective in the category of very high or high importance. With the exception of the brand strengthening objective, chi-square tests revealed a significant size effect across all objectives, with the data indicating that medium firms most often reported each objective as having very high or high importance in adopting SCRM. On the possibility of sectoral differences, the data indicate these were small and not significant for any of the eight objectives. 
Table 4 SCRM adopters that rated objectives as very high or high in importance by organisational characteristics

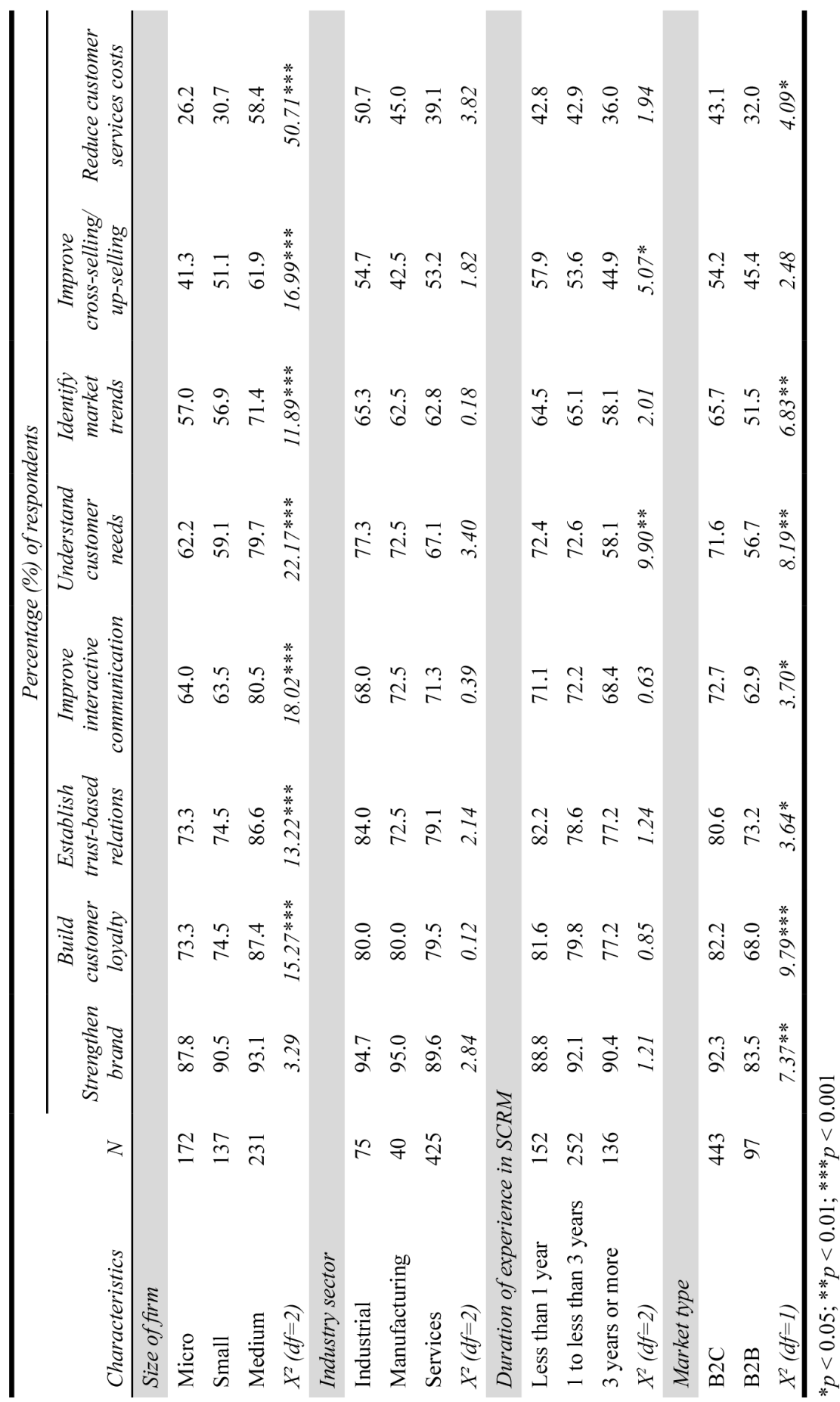


In relation to years of experience with SCRM, those adopters with less than 3 years' experience rated each objective as having very high or high importance more often than did those with 3 years or more experience, with the chi-square results being significant for only two objectives: understanding customer needs $\left(X^{2}=9.90, p<0.01\right)$ and improving cross-selling and up-selling $\left(X^{2}=5.07, p<0.05\right)$. For the type of market served (B2C or B2B), chi-square tests revealed a significant size effect across all objectives, with one exception (improve cross-selling/up-selling). In terms of this exception, more SCRM adopters (54.2\%) engaged in selling to individual customers (B2C) rated this objective as having very high or high importance compared to SCRM adopters (45.4\%) selling to other companies or divisions of their firm (B2B).

\subsubsection{Methods of sourcing or implementing a SCRM system}

In order to develop and/or implement a SCRM system, firms may adopt one or more of the following methods

1 use the firm's IT department to develop and implement the system according to the firm's needs [in-house]

2 outsource system development and implementation to an external vendor i.e. application service provider [outsourcing vendor]

3 have the system specified by the firm's IT department, then purchase an appropriate software package from an application service provider, and subsequently allocate responsibility for implementation to the firm's IT department [outsourcing vendor for developing \& in-house for implementing]

4 employ consultants to manage the planning and execution of the firm's SCRM initiative [consultants].

Respondents were asked to answer specific questions on each of the above methods in order to determine the extent to which external assistance was used in the development and implementation of SCRM. The results are shown in Table 5. Over half (53.5\%) of the SCRM adopters indicated that system development and implementation occurred in-house; and only $25.7 \%$ used an outsourcing vendor. Less than one-fifth of respondents reported the use of consultants to assist in the planning/execution of SCRM system $(18 \%)$, or the purchase of SCRM software from an external source and implementation by the firm's IT department i.e. outsourcing vendor for developing \& in-house for implementing (17\%). These results indicate a clear preference and reliance by respondents on the use of in-house methods and resources for SCRM implementation. 
Table 5 Methods of implementing a SCRM system

\begin{tabular}{|c|c|c|}
\hline Method & $N$ & $\begin{array}{l}\text { Percentage }(\%) \text { of SCRM } \\
\text { adopters }(N=540)\end{array}$ \\
\hline $\begin{array}{l}\text { Having the system developed and implemented } \\
\text { by the IT department according to the } \\
\text { company's needs }\end{array}$ & 289 & 53.5 \\
\hline $\begin{array}{l}\text { Having the system developed and implemented } \\
\text { by an outsourcing vendor (i.e. application } \\
\text { service provider) according to the company's } \\
\text { need }\end{array}$ & 139 & 25.7 \\
\hline $\begin{array}{l}\text { Having the system specified by the IT } \\
\text { department, then purchasing an appropriate } \\
\text { software package from an application service } \\
\text { provider, and subsequently having the system } \\
\text { implemented by the IT department }\end{array}$ & 97 & 18.0 \\
\hline $\begin{array}{l}\text { Employing a consultant(s) to help in the } \\
\text { planning and execution of the SCRM system }\end{array}$ & 92 & 17.0 \\
\hline
\end{tabular}

Survey question: 'Which of the following methods of sourcing and implementing a SCRM system has been used by your company? (select all that apply)'

Table 6 provides the detailed picture by organisational characteristic of the percentage of SCRM adopters for each method of sourcing/implementing SCRM. Developing and implementing a SCRM system in-house was the most common method used across the three types of firm size; however, the in-house method was reported more often by small firms compared to micro-sized and medium firms $\left(X^{2}=10.24, p<0.01\right)$. The outsourcing vendor method $\left(X^{2}=15.13\right)$ and the outsourcing vendor for developing \& in-house for implementing method $\left(X^{2}=20.35\right)$ were reported most often by medium firms $(p<0.001)$. Interestingly, the percentage of firms that reported using the consultants method to plan and manage implementation of SCRM decreased significantly with firm size $\left(X^{2}=6.08, p<0.05\right)$. The longer the duration of a firm's experience with SCRM, the more often the in-house method was reported $\left(X^{2}=5.99, p<0.05\right)$. Reporting of the use of the consultants method was significant for SCRM adopters with experience of less than 1 year $\left(X^{2}=7.06, p<0.05\right)$. In regard to the type of market served, the reporting of the in-house method was significant for B2B market-oriented SCRM adopters $\left(X^{2}=6.21\right.$, $p<0.05)$, whereas B2C market-oriented SCRM adopters tended to report the purchase of SCRM software from an outsourcing vendor which was then implemented in-house $\left(X^{2}=4.70, p<0.05\right)$. No sectoral effects were detected for any of the four methods of SCRM implementation. 
Table 6 Methods of implementing a SCRM system by organisational characteristics

\begin{tabular}{|c|c|c|c|c|c|}
\hline \multirow[b]{2}{*}{ Characteristics } & \multirow[b]{2}{*}{$N$} & \multicolumn{4}{|c|}{ Percentage (\%) of respondents in each row } \\
\hline & & $\begin{array}{c}\text { In-house } \\
\text { (developing/ } \\
\text { implementing) }\end{array}$ & $\begin{array}{l}\text { Outsourcing } \\
\text { vendor } \\
\text { (developing/ } \\
\text { implementing) }\end{array}$ & $\begin{array}{c}\text { Outsourcing vendor } \\
\text { (developing) and } \\
\text { In-house } \\
\text { (implementing) }\end{array}$ & $\begin{array}{l}\text { Consultants } \\
\text { (planning } \\
\text { and } \\
\text { execution) }\end{array}$ \\
\hline \multicolumn{6}{|l|}{ Size of firm } \\
\hline Micro & 172 & 57.0 & 19.8 & 9.9 & 21.5 \\
\hline Small & 137 & 62.0 & 19.0 & 13.9 & 19.0 \\
\hline Medium & 231 & 45.9 & 34.2 & 26.4 & 12.6 \\
\hline$X^{2}(d f=2)$ & & $10.24 * *$ & $15.13 * * *$ & $20.35 * * *$ & $6.08 *$ \\
\hline \multicolumn{6}{|l|}{ Industry sector } \\
\hline Industrial & 75 & 56.0 & 20.0 & 20.0 & 16.0 \\
\hline Manufacturing & 40 & 65.0 & 35.0 & 10.0 & 22.5 \\
\hline Services & 425 & 52.0 & 25.9 & 18.4 & 16.7 \\
\hline$X^{2}(d f=2)$ & & 2.70 & 3.09 & 1.98 & 0.93 \\
\hline \multicolumn{6}{|c|}{ Duration of experience in SCRM } \\
\hline $\begin{array}{l}\text { Less than } 1 \\
\text { year }\end{array}$ & 152 & 46.1 & 25.7 & 19.7 & 23.7 \\
\hline $\begin{array}{l}1 \text { to less than } 3 \\
\text { years }\end{array}$ & 252 & 54.4 & 26.6 & 17.1 & 13.5 \\
\hline $\begin{array}{l}3 \text { years or } \\
\text { more }\end{array}$ & 136 & 60.3 & 24.3 & 17.6 & 16.2 \\
\hline$X^{2}(d f=2)$ & & $5.99 *$ & 0.25 & 0.47 & $7.06^{*}$ \\
\hline \multicolumn{6}{|l|}{ Market type } \\
\hline B2C & 443 & 51.0 & 25.7 & 19.6 & 17.6 \\
\hline B2B & 97 & 64.9 & 25.8 & 10.3 & 14.4 \\
\hline$X^{2}(d f=1)$ & & $6.21^{*}$ & 1.00 & $4.70^{*}$ & 0.57 \\
\hline
\end{tabular}

\subsubsection{SCRM implementation-related activities}

The list of SCRM implementation-related activities reported as undertaken by respondents is shown in Table 7. The two most common activities reported by SCRM adopters were monitoring SNS for comments and conversations regarding the firm (71.9\%), and learning about social media in the context of customers $(63.7 \%)$. The least frequently reported activities were developing organisational policies and guidelines for the use of SNS by employees in responding to customer comments (30\%), and measuring the impact of social media on business results $(31.7 \%)$. 
Table $7 \quad$ SCRM implementation-related activities

\begin{tabular}{lcc}
\hline $\begin{array}{l}\text { Activity } \\
\text { Monitoring SNS for comments and conversations regarding }\end{array}$ & 388 & $\begin{array}{c}\text { Percentage (\%) of SCRM } \\
\text { adopters (N=540) }\end{array}$ \\
\hline $\begin{array}{l}\text { Learning about social media in the context of customers } \\
\text { Proactively looking for new ways of using social media to }\end{array}$ & 266 & 63.9 \\
engage with customers. & 49.3 \\
$\begin{array}{l}\text { Regularly and systematically listening to and possibly } \\
\text { responding to customer comments and conversations on } \\
\text { social media regarding the company and its products or } \\
\text { services }\end{array}$ & 262 \\
$\begin{array}{l}\text { Using SNS to collaborate and co-create content with } \\
\text { customers in order to increase brand engagement }\end{array}$ & 227 \\
$\begin{array}{l}\text { Planning and identifying ways of analysing and aggregating } \\
\text { data from social media in order to yield summary usable } \\
\text { data regarding customers and products or services }\end{array}$ & 194 & 48.5 \\
$\begin{array}{l}\text { Finding ways to use the data that the company has } \\
\text { uncovered in conversations and/or that customers have } \\
\text { volunteered through their use of social media }\end{array}$ & 182 \\
$\begin{array}{l}\text { Evaluating or measuring social media's impact on business } \\
\text { results }\end{array}$ & 171 \\
$\begin{array}{l}\text { Developing organisational policies and guidelines for the } \\
\text { use of social media by employees in responding to or joining } \\
\text { customer comments and conversations }\end{array}$ & 162 & 35.9 \\
\hline
\end{tabular}

Survey question: 'Has your company engaged in any of the following SCRM implementation-related activities? (select all that apply)'

The number of SCRM implementation-related activities reported by SCRM adopters ranged from 1 to 9 , with $42.8 \%$ using $1-3,41.6 \%$ using $4-6$ and $15.6 \%$ using $7-9$. Table 8 reports the means and standard deviations (S.D.) for the number of SCRM implementation-related activities by organisational characteristic. Size differences were small and not significant. As might be expected, the ANOVA results showed significant differences in the mean scores between different categories of sector $(F=3.33, p<0.05)$, duration of experience in managing $\operatorname{SCRM}(F=12.45, p<0.001)$ and market type $(F=10.35, p<0.001)$. Specifically, SCRM adopters in the services sector or those serving the B2C market type or having a longer duration of experience with SCRM had higher mean scores compared to SCRM adopters in other sectors or those serving the B2B market type or having less experience with SCRM. 
Table 8 The number and type of SCRM implementation-related activities by organisational characteristics

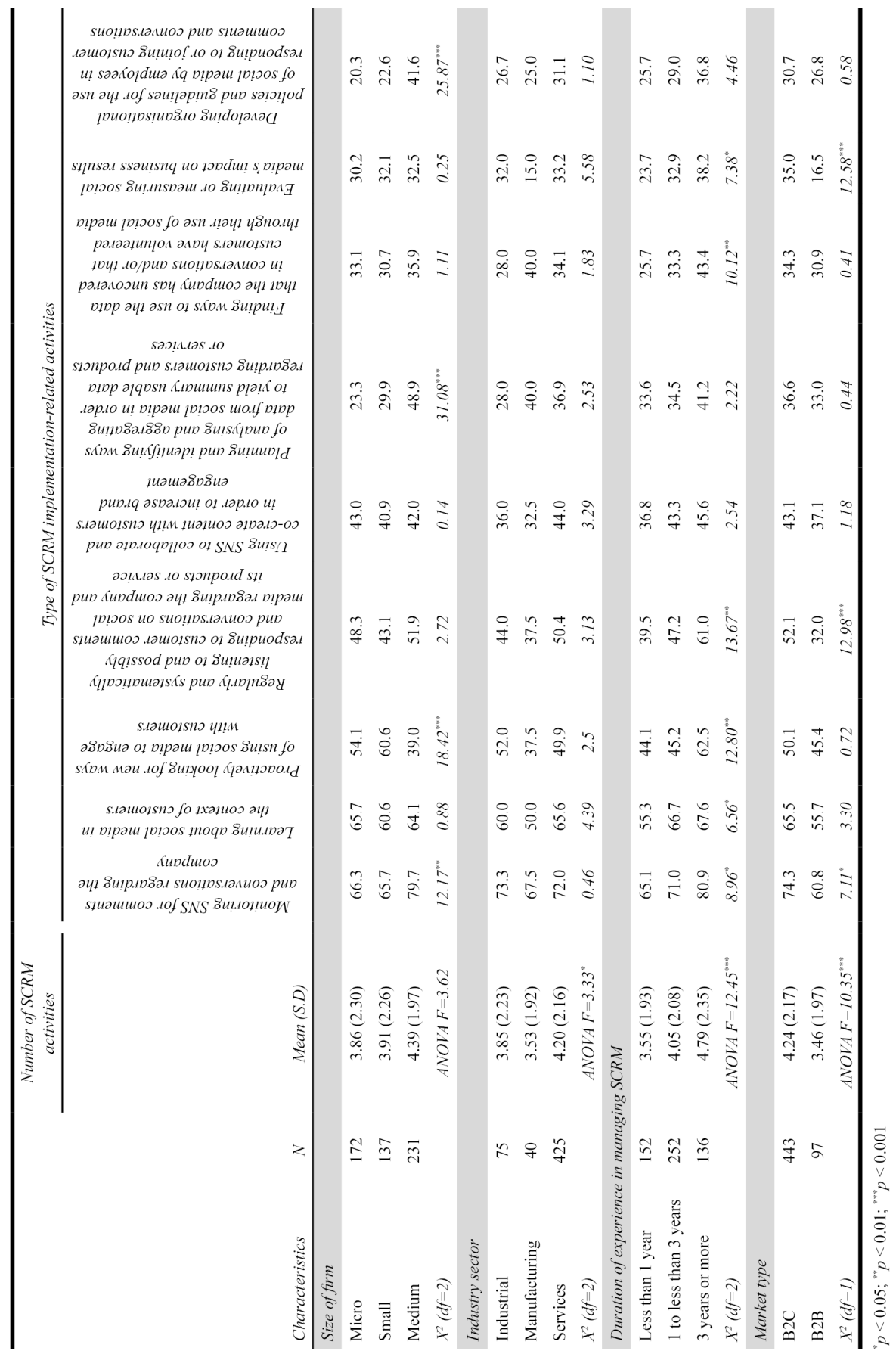


Table 8 also provides the detailed picture by organisational characteristic of the percentage of SCRM adopters for each type of SCRM implementation-related activities. Chi-square tests revealed no significant sectoral effects. The percentage of firms that reported four types of SCRM implementation activities increased significantly with firm size $(\mathrm{p}<0.001)$. These four activities included 'monitoring SNS for comments and conversations regarding the company' $\left(X^{2}=12.17\right)$, 'proactively looking for new ways of using social media to engage with customers' $\left(X^{2}=18.42\right)$, 'planning and identifying ways of analysis and aggregating data from social media in order to yield summary usable data regarding customers and products or services' $\left(X^{2}=31.08\right)$ and 'developing organisational policies and guidelines for the use of social media by employees in responding to or joining customer comments and conversations' $\left(X^{2}=25.87\right)$. Except for the latter two SCRM activities (plus 'using SNS to collaborate and co-create content with customers in order to increase brand engagement'), the longer the duration of a firm's experience with SCRM, the more often each type of activities related to SCRM implementation was reported. With regard to the type of market served, B2C marketoriented SCRM adopters tended to report three activities - including 'monitoring SNS for comments and conversations regarding the company' $\left(X^{2}=7.11\right)$, 'regularly and systematically listening to and possibly responding to customer comments and conversations on social media regarding the company and its products or services' $\left(X^{2}=12.98\right)$ and 'evaluating or measuring social media's impact on business results' $\left(X^{2}=12.58\right)$ - more than B2C market-oriented counterparts.

\subsubsection{Benefits of SCRM implementation}

Respondents were asked to report the benefits of SCRM implementation by rating the 'positive' effect for each of eight specified outcomes. Figure 2 gives the distribution for responses for three categories of level of positive effect: 'very high or high', 'medium' and 'low or no effect'. A very high or high positive effect on brand perception and reputation, customer advocacy of the firm and its products/services, customer loyalty and retention, and long-term trust-based relationships with customers were the most frequently reported outcomes ( $20 \%$ or more of SCRM adopters). Interestingly, if these results are juxtaposed with the data on SCRM objectives (Figure 1), which show $80 \%$ or more of respondents identified these outcomes as being of very high or high importance, it suggests a substantial gap between what was expected in terms of outcomes and what was delivered. In contrast, the data in Figure 2 show that over half of SCRM adopters reported a low or no positive effect on sales revenue through cross-selling and up-selling $(61.7 \%)$, and on costs of customer services (56.9\%); these results are consistent with the data on objectives (Figure 1) which show these two specific objectives rated as having low or no importance by the highest percentage of SCRM adopters. 
Figure 2 Outcomes of SCRM implementation by level of 'positive' effect (\% of SCRM adopters: $\mathrm{N}=540)$

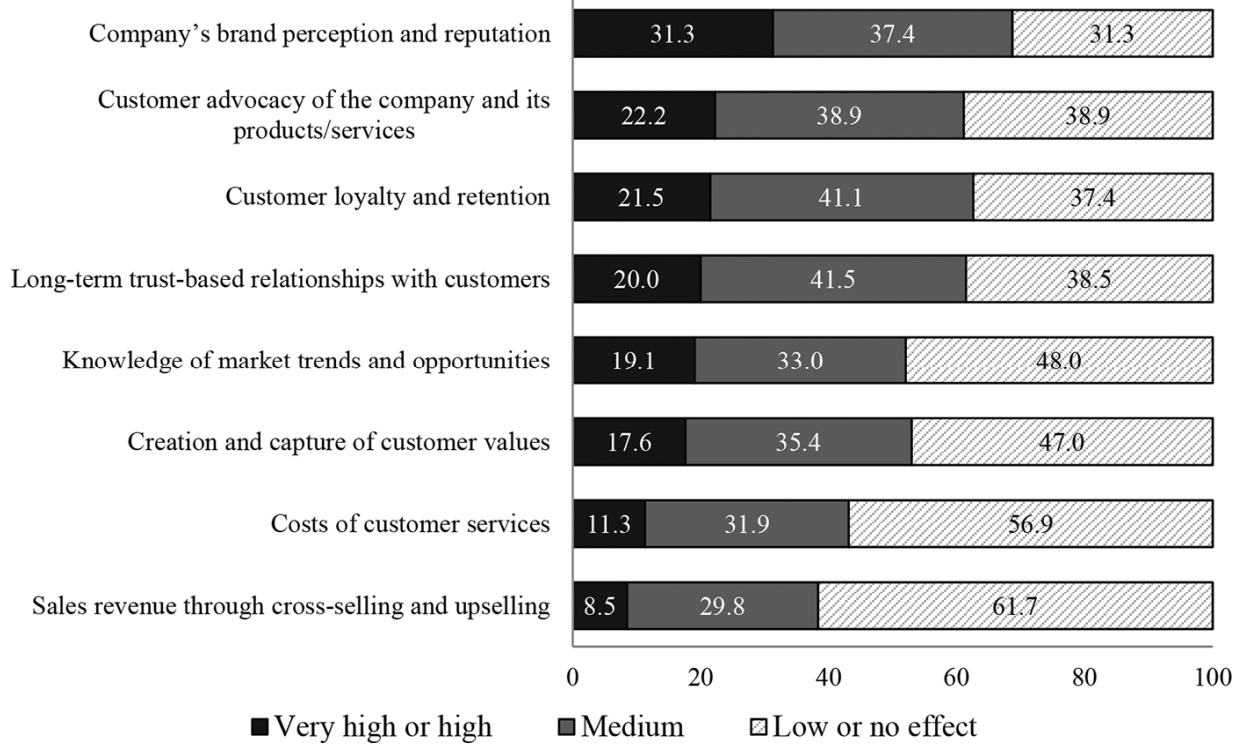

Survey question: 'How implementing SCRM in your company had a 'positive' effect on any of the following?'

Table 9 provides the detailed picture by organisational characteristic of the percentage of SCRM adopters that rated the level of benefit (i.e. the positive effect on each outcome) as being very high or high. With the exception of customer services costs, chi-square tests revealed a significant positive association between the duration of a firm's experience in managing SCRM and the positive effect on each outcome ( $X^{2}$ values ranging from 5.41 to $20.74, p<0.05)$. These results support the view that the benefits of SCRM are likely to accrue over the long term. Medium firms, more often than micro-sized and small firms, reported a benefit from SCRM in relation to customer services costs $\left(X^{2}=9.22\right.$, $p<0.01$ ). In terms of type of market served, B2C market-oriented SCRM adopters most often reported a customer services costs benefit $\left(X^{2}=3.08, p<0.05\right)$, as well as a benefit for brand perception $\left(X^{2}=5.11, p<0.05\right)$. Sectoral differences were small and not significant. 
Table 9 SCRM adopters that rated the level of benefit as very high or high in importance by organisational characteristics

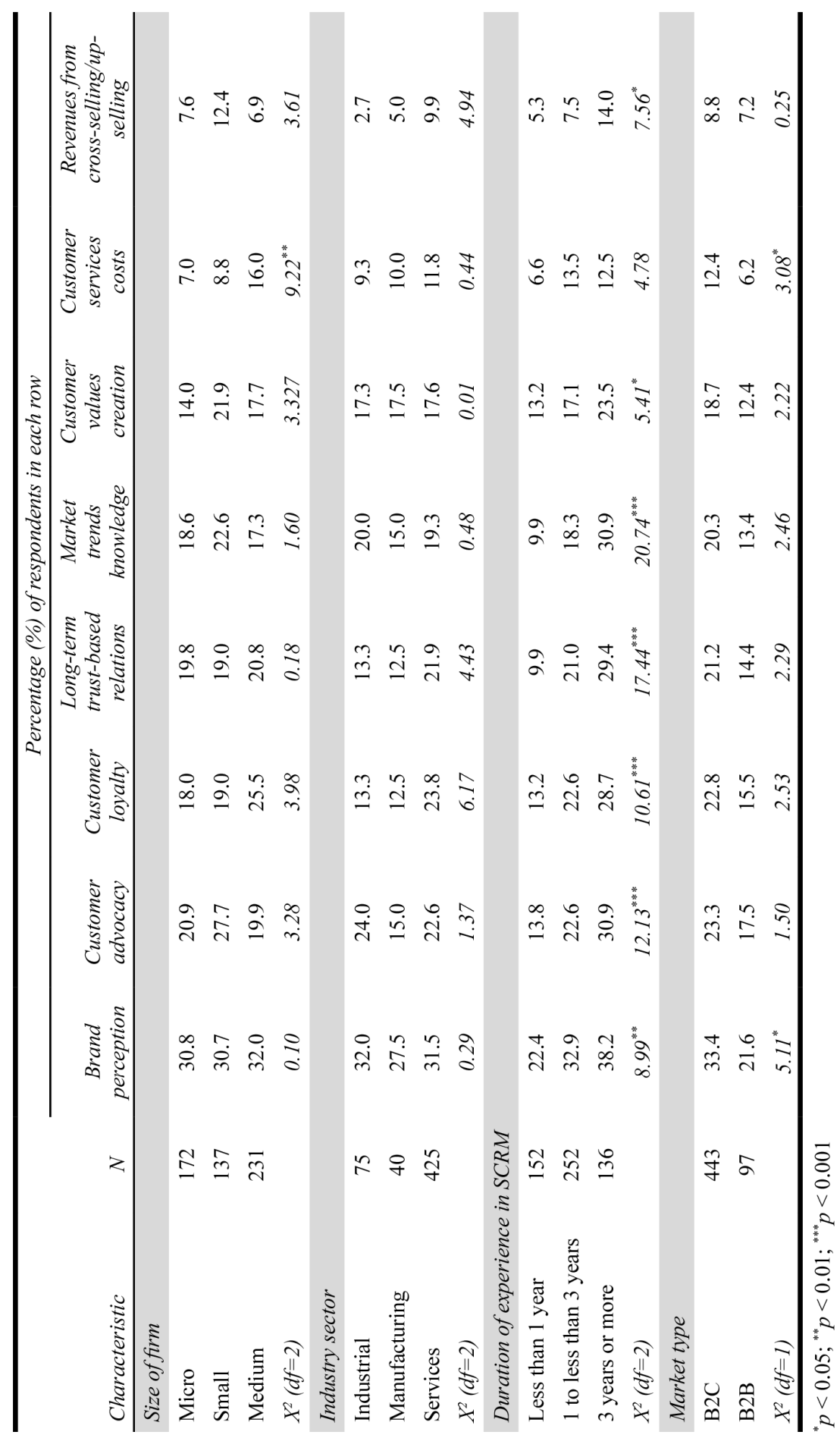




\subsubsection{Barriers to SCRM implementation}

Respondents were asked to rate the importance of each of 12 factors as constraints on, or barriers to SCRM implementation. Figure 3 gives the distribution of responses for three categories of degree of importance: 'very high or high', 'medium' and 'low or not experienced'. The factors reported by the highest percentages of SCRM adopters as having very high or high importance were as follows: time-consuming to manage/monitor SNS (60.4\%), lack of information on how to effectively implement SCRM (36.3\%), lack of skills and qualified personnel (33\%) and lack of information on how to select appropriate social media tools (29.6\%). Notably, a majority of SCRM adopters indicated that they had little or no experience of technological barriers $(64.3 \%)$, high financial costs $(56.5 \%)$ and misuse of SNS by staff $(58 \%)$ as impediments to SCRM implementation.

Figure 3 Barriers to SCRM by degree of importance ( $\%$ of SCRM adopters: N=540)

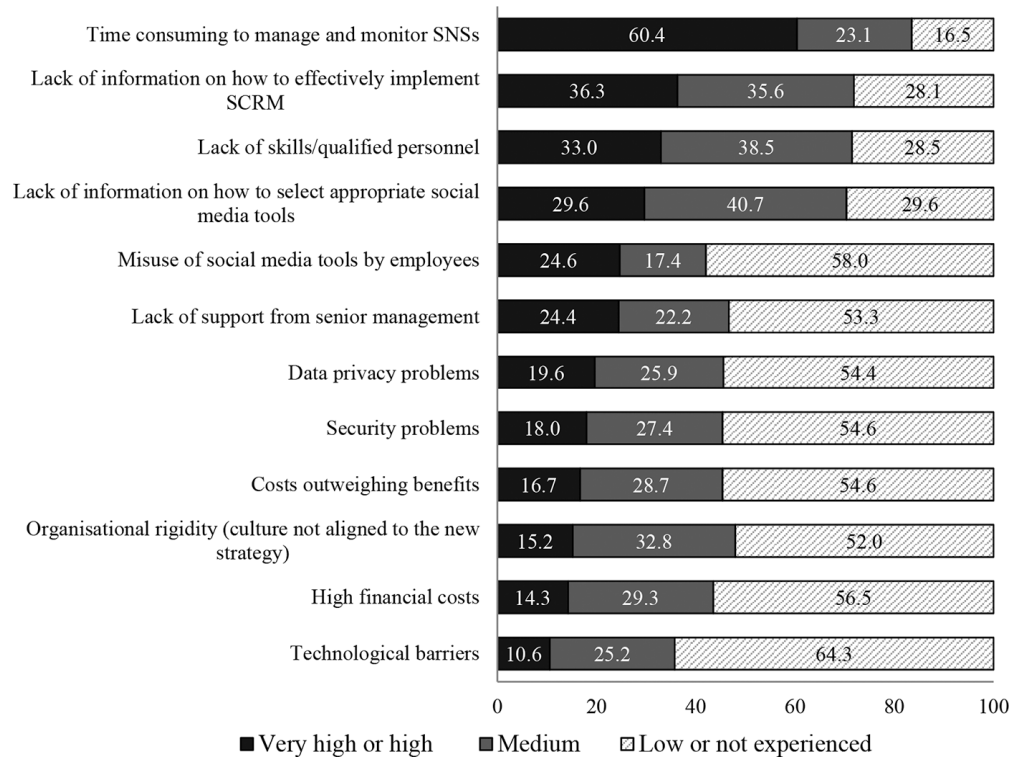

Survey question: 'How important were the following factors as 'constraints' on your company's implementation of SCRM?'

Table 10 provides the detailed picture by organisational characteristic of the percentage of SCRM adopters that rated the importance of each factor as having very high or high importance as a barrier to SCRM. Chi-square tests revealed a significant positive size effect $(p<0.05)$ on five factors as barriers: misuse of SNS by staff $\left(X^{2}=68.40\right)$; lack of support from senior management $\left(X^{2}=18.07\right)$; data privacy problems $\left(X^{2}=21.06\right)$; security problems $\left(X^{2}=26.76\right)$ and organisational rigidity i.e. culture not aligned to the new strategy $\left(X^{2}=6.08\right)$. In comparison to micro-sized and small firms, medium firms were more likely to report these factors as having very high or high importance as barriers to SCRM implementation. With regard to market type, B2C market-oriented SCRM adopters most often reported lack of information on how to select appropriate social media tools $\left(X^{2}=5.81\right)$, data privacy problems $\left(X^{2}=9.23\right)$ and security problems $\left(X^{2}=8.74\right)$ at $p<0.01$. No sectoral effect was detected whilst the duration of 
experience in managing SCRM was only significant for data privacy issues $\left(X^{2}=6.48\right)$. The highest share of SCRM adopters reporting data privacy issues was those with one to less than 3 years of experience with SCRM.

Table 10 SCRM adopters that rated factors as barriers with very high or high importance by organisational characteristics

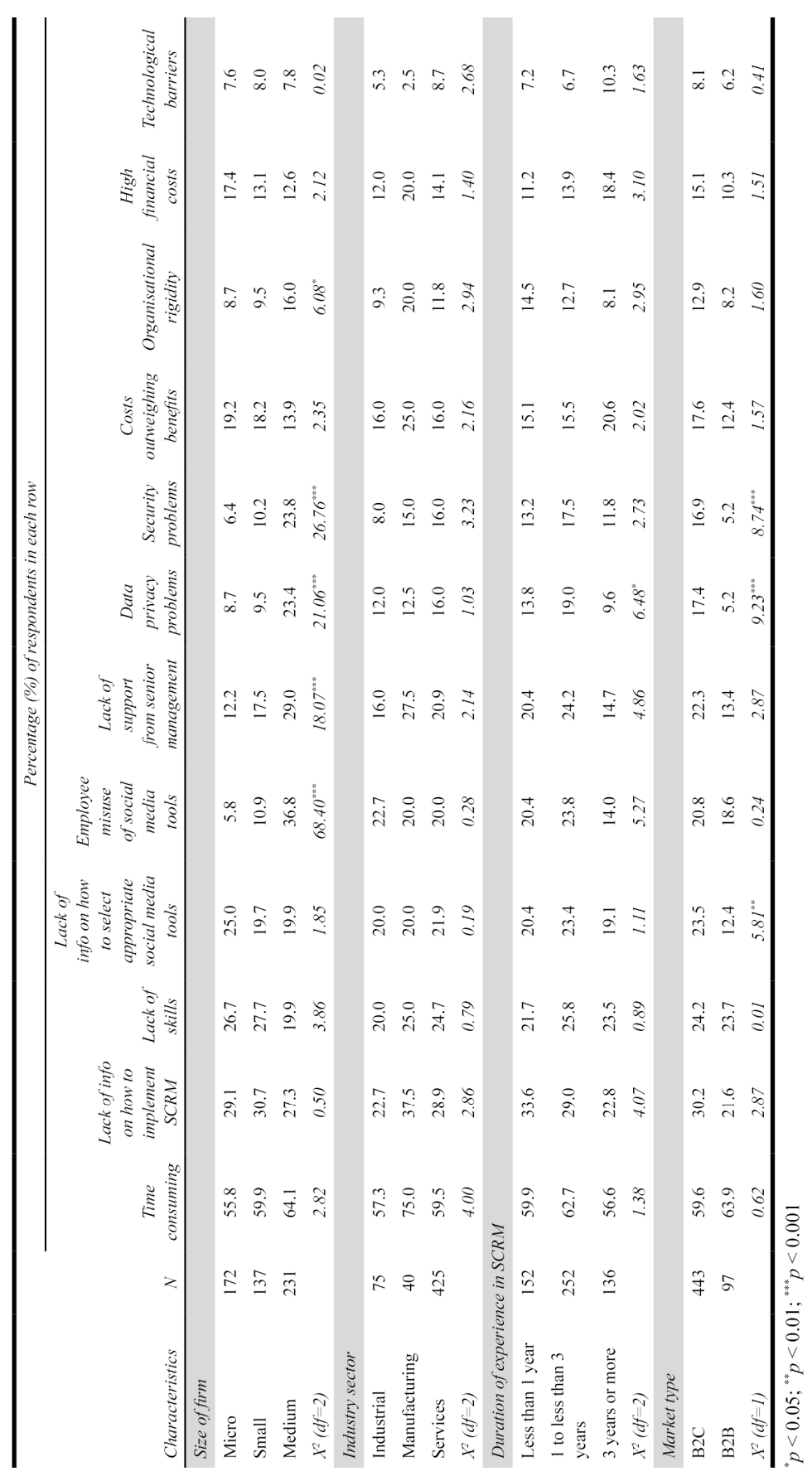




\section{Discussion and conclusions}

This paper makes a significant contribution to research on SCRM in the field of information systems, by presenting the results of the first large-scale survey-based study in Australia that explores the role and nature of SCRM in SMEs. Using a sample of 967 SMEs across all industry sectors, we found the adoption level for SCRM to be relatively low with only a slight majority $(55.8 \%)$ of Australian SMEs in the study reporting its adoption (of which $75 \%$ having less than 3 years of experience in managing SCRM). In addition, the reported approach to SCRM adoption has been relatively ad hoc, superficial (even primitive) and usually not supported by a formal integrated strategy and policy framework. Even so, it appears that Australian SMEs are increasingly taking advantage of social networking technologies and SNS to manage customer relationships. Our findings reveal that differences in SCRM adoption by SMEs can be distinguished according to industry sector and type of market (B2C and B2B). Specifically, SMEs in the services sector (especially arts and recreation services; retail trade and accommodation/food services) reported engagement in SCRM more often than SMEs in the manufacturing and industrial sectors. This may be because SMEs in the services industry sector are more customer-focused, and as a consequence find it is easier to understand the potential added value that a shift to SCRM offers for balancing the power customers now have via online social networking for communicating and sharing information. This explanation is also supported by our finding of a significantly higher proportion of B2C market-oriented SMEs that adopted SCRM, compared to those with a $\mathrm{B} 2 \mathrm{~B}$ market orientation.

Of the total number of SMEs surveyed, only SCRM adopters (540 SMEs) were asked a series of questions in relation to SCRM implementation. Key study findings include the following:

- $\quad$ Social networking sites (SNS) used with SCRM: On average, SMEs in our sample used three SNS for SCRM purposes, with Facebook dominating (87.2\% of SCRM adopters reporting the use of it) followed by Google + , LinkedIn and Twitter (each about 50\%). Medium-sized firms used Facebook and Google+ more than (but used LinkedIn less than) small and micro-sized firms. Compared to those serving the B2B market type, B2C market-oriented firms were more likely to deploy Facebook but less likely to deploy LinkedIn and SlideShare. The findings also indicated that the longer the duration of a firm's experience in managing SCRM, the greater the variety of social networking tools used.

- $\quad$ Objectives for SCRM engagement: Consistent with prior research (Acker et al., 2011; Greenberg, 2009), the findings reveal that the most important objectives for SCRM adoption by Australian SMEs were to strengthen a company's brand (reported by $90.7 \%$ ), building trust and customer loyalty (79.6\%) and establishing trust-based relationships with customers $(79.3 \%)$. The objectives of SCRM rated most often as of low or no importance were as follows: reduction of costs of customer services (39.4\%), and improvement of cross-selling and up-selling of product or service offerings (20\%). Whilst these results vary by business size and tend to reflect a complementarity between SCRM and the B2C market-orientation, they do suggest that for Australian SMEs the focus of SCRM adoption is more on acquiring new customers and retaining existing customers than on enhancing customer profitability. 
- Methods of sourcing or implementing SCRM: Over half (53.5\%) of SCRM adopters reported the use of an in-house IT department for development and implementation. Developing a SCRM system in-house was the approach most often reported by micro-sized and small firms (compared to medium firms), and was the predominant approach reported by SMEs with a B2B market-orientation and those having a greater duration of experience in managing SCRM. SCRM adopters with a B2C market-orientation tended more often to purchase SCRM software from an outsourcing vendor (application service provider) but to implement in-house. The reported use of external consultants was in inverse proportion to firm size i.e. the smaller the business, the more likely it reported the use of consultants in the planning and implementation of SCRM. This finding supports the possibility that a scarcity of knowledge and resources for determining an appropriate approach to SCRM, a resource situation more likely to be found in micro-sized and small firms, may be a significant barrier to effective SCRM adoption. In comparison with their smaller counterparts, medium firms (perhaps due to greater availability of financial resources) tended to report having used an outsourcing vendor for SCRM development.

- SCRM implementation-related activities: On average, SCRM adopters engaged in four activities to accomplish SCRM implementation. The reported numbers of such activities increased with the duration of experience in managing SCRM, and were greater in the services sector and for B2C market-oriented SCRM adopters. The most common activities reported were as follows: monitoring SNS for conversations regarding the firm/product (71.9\%); learning about SNS in the context of customers (63.7\%); proactively looking for new ways of using SNS to engage with customers (49.3\%) and regularly responding to customer conversations on SNS regarding the firm and its products or services (48.5\%). The two least common activities (reported by less than one-third of SCRM adopters) were as follows: measuring the impact of social media on business results and developing organisational policies and guidelines for the use of SNS by employees. These findings are consistent with similar recent findings by Aaltonen et al. (2013) showing that approximately $70 \%$ of European SMEs do not have a formal policy relating specifically to social media. Overall, the types of activities employed in relation to SCRM implementation vary by firm size, market orientation and years of experience with SCRM.

- Benefits of SCRM implementation: Although $80 \%$ or more of SCRM adopters reported strengthening brand, and building trust and customer loyalty, as major objectives for SCRM engagement, only around $20 \%$ of them perceived a major benefit in relation to these objectives following SCRM implementation. These findings suggest that there is a substantial gap between intentions (objectives) and benefits (positive effects) of SCRM. Based on our chi-square results, a possible explanation may be found in the role of 'time' as a contingency factor affecting the objectives-benefits relationship, where the full benefits from implementing SCRM may only be realised over the long term.

- Barriers to SCRM implementation: Implementing SCRM effectively requires dealing associated barriers and constraints. In this study, the length of time required to manage and monitor SNS was reported as a major barrier by a large majority $(60.4 \%)$ of SCRM adopters, followed by a lack of information on how to effectively 
implement SCRM (36.3\%), and a lack of skills and qualified personnel (33\%). Interestingly, our findings revealed that more than 56\% of SCRM adopters with limited experience reported technological barriers and high financial costs as a constraint on their SCRM implementation. The reporting of these perceived barriers to SCRM adoption might in part explain the relatively low level of SCRM adoption by Australian SMEs in this study; they are also consistent with the view that adoption of SCRM may be linked more to technology maturity, market type and demand, rather than the availability of new technologies perceived as too high in cost (Wang and Owyang, 2010). Other perceived barriers to SCRM implementation, such as organisational rigidity, data privacy/security issues, lack of management support and staff misuse of SNS, were more often reported as size of firm increased.

\subsection{Implications for research}

In presenting the findings of our exploratory investigation of the role and nature of SCRM in SMEs, we address a vital business topic on which there is a dearth of empirical research (Harrigan and Miles, 2014; Newby et al., 2014). The empirical evidence presented in this study shows that while a very small majority of Australian SMEs are implementing SCRM, there is still a considerable number of SMEs that seemingly remain unaware of its benefits, and have yet to embrace the strategic business opportunities it provides for building and enhancing customer engagement. Four implications for SCRM research are apparent in our findings. First, the level of SCRM adopted by SMEs is relatively superficial (even primitive) and ad hoc in the absence of a formal integrated SCRM strategy and policy framework. Second, while our findings suggest that SMEs perceive benefits gained from SCRM, especially in terms of building brand and customer loyalty, these benefits may become apparent only over the long term, thus making the cost-benefit risk appear larger in the short term. Third, there appears to be a lack of understanding on the part of SMEs of how SCRM might best be implemented effectively to generate improved profits and other important business outcomes such as retaining control over a firm's market presence. Finally, a lack of available time, knowledge and resources, for managing, monitoring and utilising SCRM and the associated social networking tools, appears to constitute the major impediment to successful adoption by SMEs. The study findings, therefore, provide several small but significant starting points for refining and potentially revitalising knowledge of how SCRM could be effectively adopted by SMEs.

\subsection{Implications for practice}

Since the business case for SCRM in Australia has not yet been established, the level of SCRM adoption, types of social networking tools used with SCRM, objectives for SCRM engagement, methods of implementing a SCRM system, SCRM implementation-related activities, as well as the benefits and barriers related to SCRM implementation have yet to be determined. In this light, our findings contain practical value for SME ownermangers of firms wishing to adopt SCRM. We also believe our findings should be of interest to government policymakers wishing to provide SMEs with information and support tailored to fit their distinctive organisational characteristics (e.g. entrepreneurial, owner-manager operated, flexible, etc.) and assist SMEs in bridging the gap between the promise and realities of SCRM adoption. Until that support is forthcoming, those SMEs 
which are willing and able to 'self-help' in successfully adopting SCRM are likely to gain a significant strategic advantage over those SMEs which lag behind.

\subsection{Limitations and future research directions}

While this study has raised many important issues, it also has limitations. The study findings are limited by a focus on a single national economic context and the use of cross-sectional and self-reported survey data. These study characteristics limit the generalisability of our findings. For instance, the results reflect the specific characteristics of Australian companies and may not thus be generalisable to companies in other economies. Furthermore, although the perceptions of owner-managers or senior managers are widely accepted as accurate reflections of SCRM practices, the subjective and potentially idiosyncratic nature of their reporting of SCRM implementation activities, objectives, barriers and benefits should be borne in mind when interpreting the findings.

Our study points to the need for future research to help reveal the inner workings of the SCRM complex process and demonstrate the practical value of such an initiative in relation to firm performance. Besides replication of our study in other economies for the purposes of comparative study, future research could investigate the SCRM phenomenon in SMEs in greater and more critical depth using multiple and objective sources of data, deploying intensive and longitudinal research designs, and employing advanced statistical and/or mathematical techniques. Such research would be of great value in supporting the effective implementation of SCRM. Future research that conducts an in-depth comparison of SCRM adopters and non-SCRM adopters could also yield useful insights into the factors (e.g. resources and capabilities) required for or involved in successful adoption of SCRM. Since SCRM benefits are typically intangible and hard to measure, quantifying and translating these benefits into monetary value for SMEs presents an exciting challenge for future research.

\section{References}

Aaltonen, S., Kakderi, C., Hausmann, V. and Heinze, A. (2013) 'Social media in Europe: lessons from an online survey', Paper presented at the 18th UKAIS Conference, UKAIS, United Kingdom.

Acker, O., Grone, F., Akkad, F., Potscher, F. and Yazbek, R. (2011) 'Social CRM: how companies can link into the social web of consumers', Journal of Direct, Data and Digital Marketing Practice, Vol. 13, No. 1, pp.1-12.

Ang, L. (2011) 'Is SCRM really a good social media strategy?', Journal of Database Marketing \& Customer Strategy Management, Vol. 18, No.3, pp.149-153.

Askool, S. and Nakata, K. (2011) 'A conceptual model for acceptance of social CRM systems based on a scoping study', AI \& Society, Vol. 26, No. 3, pp.205-220.

Australian Bureau of Statistics (2001) Small Business in Australia, Australian Bureau Statistics, Catalogue. 1321.0, Australian Government Printers, Canberra.

Baird, C.H. and Parasnis, G. (2011) From Social Media to Social CRM: Reinventing the Customer Relationship, the Second in a Two-Part Series, IBM Global Business Services, USA.

Barnad, S., Bothma, C. and Cant, M. (2017) 'The identification of criteria for the optimal use of Facebook pages for marketing purposes: a South African perspective', Journal of Business and Retail Management Research, Vol. 11, No. 2, pp.65-78.

Berthon, P., Pitt, L. and Campbell, C. (2008) 'Ad Lib: when customers create the AD', California Management Review, Vol. 50, No. 4, pp.6-30. 
Bordonabe-Juste V., Lucia-Palacios L. and Polo-Redondo Y. (2012) 'The influence of organizational factors on e-business use: analysis of firm size', Marketing Intelligence \& Planning, Vol. 30, No. 2, pp.212-229.

Boyles, T. (2011) 'Small business and Web 2.0: hope or hype?', Entrepreneurial Executive, Vol. 16, pp.81-96.

Burgess, S., Sellitto, C. and Karanasios, S. (2009) Effective Web Presence Solutions for Small Businesses: Strategies for Successful Implementation, IGI Global, Hershey, PA.

Burgess, S., Sellitto, C, Cox, C. and Buultjens, J. (2015) 'Strategies for adopting consumergenerated media in small-sized to medium-sized tourism enterprises', International Journal of Tourism Research, Vol. 17, No. 5, pp.432-441.

Buttle, F. and Maklan, S. (2015) Customer Relationship Management: Concepts and Technologies, Routledge, London.

Cappuccio, S., Kulkarni, S., Sohail, M., Haider, M. and Wang, X. (2012) 'Social CRM for SMEs: current tools and strategy', in Khachidze, V., Wang, T., Siddiqui, S., Liu, V., Cappuccio, S. and Lim, A. (Eds.) Contemporary Research on E-Business Technology and Strategy, Springer Berlin Heidelberg, pp.422-435.

Carson, M. (2013) An Expanding Network of Risk and Opportunity: How UK SMEs and UnderEstimating the Growing Complexity of Technology, The Economist Intelligence Unit, Zurich.

Cooper, C.L. and Burke, R.J. (2011) Human Resource Management in Small Business: Achieving Peak Performance, Edward Elgar, Cheltenham.

Department of Industry, Innovation, Science, Research and Tertiary Education (2012) Australian Small Business: Key Statistics and Analysis, Australian Government Printers, Canberra.

Dutot, V. (2013) 'A new strategy for customer engagement: how do French firms use social CRM?', International Business Research, Vol. 6, No. 9, pp.54-67.

Dyerson, R., Harindranath, G. and Barnes, D. (2009) 'National survey of SMEs' use of IT in four sectors', Electronic Journal Information Systems Evaluation, Vol. 12, No. 1, pp.39-50.

European Commission (2005). The New SME Definition: User Guide and Model Declaration, European Commission, Luxembourg.

Faase, R., Helms, R. and Spruit, M. (2011). 'Web 2.0 in the CRM domain: defining social CRM', International Journal of Electronic Customer Relationship Management, Vol. 5, No. 1, pp.1-22.

Fux, M., Mathieu, D. and Myrach, T. (2007). 'Cooperative customer relationship management (CRM), in alpine tourist destinations', Paper presented at the European Conference of Information Systems (ECIS), Gallen.

Greenberg, P. (2009) CRM at the Speed of Light: Social CRM Strategies, Tools, and Techniques for Engaging Your Customers, 4th ed., McGraw-Hill Osborne Media, USA.

Greenberg, P. (2010) 'The impact of CRM 2.0 on customer insight', Journal of Business and Industrial Marketing, Vol. 25, No. 6, pp.410-419.

Harrigan, P. and Miles, M. (2014) 'From e-CRM to s-CRM: critical factors underpinning the social CRM activities of SMEs', Small Enterprise Research, Vol. 21, No. 1, pp.99-116.

Huang, M.H. and Wang, E.T.G. (2013) 'Marketing is from mars, IT is from venus: aligning the worldviews for firm performance', Decision Sciences, Vol. 44, pp.87-125.

Keuky, R. and Clarke, S. (2011). Socializing CRM: Merits and Approaches to Deploying Social CRM solution, Capgemini. Available at: http://www.capgemini.com $/ \mathrm{m} / \mathrm{en} / \mathrm{t} / \mathrm{Socializing}$ CRM.pdf (accessed date: 22 May 2016).

Kotadia, H. (2010) '5 Lessons social CRM can learn from CRM', Blog on Big Data and Analytics. Available at: http://hkotadia.com/archives/2411 (accessed date: 2 March 2017).

Kim, H.D., Lee, I. and Lee, C.K. (2013) 'Building Web 2.0 enterprises: a study of small and medium enterprises in the United States', International Small Business Journal, Vol. 31, No. 2, pp.156-174. 
Knox, S., Maklan, S., Payne, A., Peard, J. and Ryals, L. (2003) Customer Relationship Management: Perspectives from the Marketplace, Butterworth Heinemann, Great Britain.

Leary, B. (2008) Social CRM: Customer Relationship Management in the Age of the SociallyEmpowered Customer, Social CRM - The Whitepaper, CRM Essentials LLC. Available at: http://crm2.typepad.com/brents_blog/2008/10/social-crm----1.html, Sage CRM Solutions.

Mangold, G.W. and Faulds, D.J. (2009) 'Social media: the new hybrid element of the promotion mix’, Business Horizons, Vol. 52, No. 4, pp.357-365.

Marolt, M., Pucihar, A. and Zimmermann, H. (2015) 'Social CRM adoption and its impact on performance outcomes: a literature review', Organizacija, Vol. 48, pp.432-441.

Maecker, O., Barrot, C. and Becker, U. (2016) 'The effect of social media interactions on customer relationship management', Business Research, Vol. 9, No. 1, pp.133-155.

Mosadegh, M. J. and Behboudi, M. (2011) 'Using social network paradigm for developing a conceptual framework in CRM', Australian Journal of Business and Management Research, Vol. 1, No. 4, pp.63-71.

Newby, M., Nguyen, H. and Waring, S. (2014) 'Understanding customer relationship management technology adoption in small and medium-sized enterprises: an empirical study in the USA', Journal of Enterprise Information Management, Vol. 27, No. 5, pp.541-560.

Olupot, C., Kituyi, G. and Noguer, J. (2014) 'Factors affecting the adoption of electronic customer relationship management information systems in SMEs', Journal of Studies in Social Sciences, Vol. 8, No. 1, pp.25-45.

Olszak, C. and Bartus, T. (2013) 'Multi-agent framework for social customer relationship management systems', Issues in Informing Science and Information Technology, Vol. 10, pp.367-387.

Payne, A. and Frow, P. (2005) 'A strategic framework for customer relationship management', Journal of Marketing, Vol. 69, No. 4, pp.167-176.

Payne, A. and Frow, P. (2006) 'Customer relationship management: from strategy to implementation', Journal of Marketing Management, Vol. 22, pp.135-168.

Pew Research Centre (2016) Smartphone Ownership and Internet Usage Continues to Climb in Emerging Economics. Available at: http://www.pewglobal.org/2016/02/22/smartphoneownership-and-internet-usage-continues-to-climb-in-emerging-economies/ (accessed date: 2 March 2017).

Rappaport, S.D. (2010) 'Cutting edges - listening-led marketing science, media strategies, and organizations', Journal of Advertising Research, Vol. 50, No. 3, pp.305-315.

Reinhold, O. and Alt, R. (2012) 'Social customer relationship management: state of the art and learnings from current projects', Paper presented at the 25th Bled eConference eDependability: Reliable and Trustworthy eStructures, eProcesses, eOperations and eServices for the Future, Slovenia.

Sarner, A., Thompson, E., Dunne, M. and Davies, J. (2010) Top Use Cases and Benefits for Successful Social CRM, Gartner, USA.

Sarner, A., Thompson, E., Mann, J., Dunne, M., Davies, J., Fletcher, C. and Maoz, M. (2011) Magic Quadrant for Social CRM, Gartner.

Sensis (2014) Sensis E-Business Report: The Online Experience of Small and Medium Enterprises. Sweeney Research, Australia. Available at: https://www.sensis.com.au/content/dam/sas/PDF directory/Sensis-eBusiness-Report-2014.pdf (accessed date: 30 April 2016).

Sensis (2016) Sensis Social Media Report May 2016 How Australian People and Businesses Are Using Social Media, Sensis Social Media Report, Australia. Available at https://www.sensis. com.au/asset/PDFdirectory/Sensis_Social_Media_Report_2016.PDF (accessed date: 2 March 2017).

Stone, M. (2009) 'Staying customer-focused and trusted: Web 2.0 and Customer 2.0 in financial services', Journal of Database Marketing \& Customer Strategy Management, Vol. 16, No. 2, pp.101-131. 
Straker, K. and Wrigley, C. (2016) 'Emotionally engaging customers in the digital age: the case study of "Burberry love", Journal of Fashion Marketing and Management, Vol. 20, No. 3, pp.276-299.

United Nations Industrial Development Organization (2005) Technical Working Paper Series: Small and Medium Enterprises Branch, Working Paper 5, United Nations Industrial Development Organization. Available at: https://www.unido.org/fileadmin/user_media/ Publications/Pub_free/Combining_strengths_synergies_between_cluster_development_and_m icrofinance.pdf (accessed date: 28 March 2016).

Wang, R. and Owyang, J. (2010) Social CRM: The New Rules of Relationship Management, Altimeter Group, USA.

Wielicki, T. and Arendt, L. (2010) 'A knowledge-driven shift in perception of ICT implementation barriers: comparative study of US and European SMEs', Journal of Information Science, Vol. 36, pp.162-174.

Woodcock, N., Green, A. and Starkey, M. (2011) 'Social CRM as a business strategy', Journal of Database Marketing and Customer Strategy Management, Vol. 18, No. 1, pp.50-64.

Yawised, K., Marshall, P.H. and Stockdale, R. (2013) 'Social CRM: a review of academic and practitioner literatures and research agendas', Proceedings of the Malaysian Conference on Information Systems MCIS2013, Kota Kinabalu, Sabah, Malaysia, 101-107. 